yards from the outrage, begged to be admitted, and when refused, and feeling faint, hid the mail bags, and after "coming to" crawled to another house, prayed for admission, and to send for a priest. Being again refused, he "dropped down to die." He has no idea how long he lay there, but hearing a car pass he made an effort, and got to the road, where he was found in a fainting state by the police sent to look for him. The bullets removed were $\cdot 450$, or about the same size as those used for the British bulldog revolver. I am, Sirs, yours faithfully,

County Infirmary, Longford, oct. 3rd, 1889.

N. MAYNE.

\section{EXFOLIATION OF ALVEOLAR PROCESSES.} To the Editors of THE LANCET.

SIRs,-I see Mr. R. Clement Lucas, in giving notes of two cases of necrosis of the alveolar processes following measles, which appeared in your last impression, says that he does not know of any case of typhoid fever resulting in exfoliation of the alveolar processes of the jaws. As such a case occurred in my practice a year ago, it is perhaps of sufficient interest to place on record.

W. H- a lad of sixteen, sent for me on Aug. 30th, 1888. I found a well-marked case of typhoid fever, and the patient for a fortnight, or the latter half of September, was in a semi-conscious condition, requiring rousing for a part of that time to take nourishment \&c. On Oct. 10th the left half of the lower maxilla was noticed to be swollen, and afterwards there was fetid breath with foul-smelling mouth and gumis. On the 17th he had pulled out the two lower left incisors, and the canine molars were found to be loose, whilst the alveolar process was also loose and evidently necrosed. He was sent to the London Hospital, his friends not being able to stand the drain on their resources, and the alveolar process, including the sockets of all the teeth of the left half of the lower maxilla, eventually was taken away, leaving the lad one side of his face fresh and juvenile and the other side very grandmotherly looking indeed.

I am, Sirs, yours truly,

MILLICE CULPIN, L.R.C.P., L.R.C.S.Edin.

Stamford-hill, Oct. 5th, 1889.

\section{NAPHTHALIN.}

To the Editors of THE LANCET.

SIRS,-May I ask for space to add my testimony to the value of naphthalin in the class of case Dr. Angel Money refers to in his letter published in your last issue? In conjunction with the diet advocated by him, I have found nothing so serviceable as the drug in question. It is equally serviceable in the epidemic infantile diarrhœa for which Nottingham occupies an unenviable position, together with Leicester and Oldham.

I am, Sirs, your obedient servant,

Nottingham, Oct. 7th, 1889. LEWIS W. MARSHaLL.

\section{MANCHESTER.}

(From OUR OWN CoRREspondent.)

\section{The Session 1889-90}

ON all sides the work of the coming session has begun. The Owens College had its opening day on the lst inst., when Professor Schuster delivered the inaugural address, taking for his subject, "University Teaching in its relation to the Industrial Application of Science." This makes the fortieth session of the College, and the few who can look back and remember the first of these must be struck by the rapid and wonderful strides the College has made in arriving at its present position. On the same day the half-yearly meeting of the court of governors was held, an interesting feature of which was the presentation to the College by a number of subscribers of a portrait of Mr. Alfred Neild, who for a considerable length of time has been its treasurer. The financial report for the past year was satisfactory, the expenditure having kept within the income. On the evening of the same day the medical department of the College had its own special opening in the shape of a soirée, at which nearly a thousand visitors were present. The guests were received by the dean of the medical school (Dr. Young), and several nembers of the court of governors \&c. Subsequently the dean presented the report for the past year, which shows a highly satisfactory condition of the school from every point of view. Various exhibits, demonstrations, drawings \&c. were provided for the amusement and instruction of the visitors, and Professor Dreschfeld gave a very interesting résumé of our present knowledge concerning leprosy. On Wednesday, the following evening, the first meeting of the Medical Society was held, and, following a practice which appears to be becoming common, of inviting gentlemen from a distance to give papers at the opening meeting of our societies, Dr. Hughlings Jackson was asked to visit Manchester, and delivered an address upon "Respiratory, Toxic, and Traumatic Convulsions." On Friday evening next the annual medical dinner will take place at the Queen's Hotel, under the presidency of Dr. Little, and after then we may hope to settle down steadily to work all round.

\section{The Proposed New Hospital.}

It is with great regret that I have to record the fact that the munificent offer of the Whitworth trustees to Owens College of a sum of some $£ 70,000$ has been lost. The trustees undertook to provide money to erect a hospital with sixty beds, and endow it with $£ 2000$ per annum, to become the property of the College, but they wished it to be more or less connected with the Royal Infirmary, the latter body to take an active share in its management. After nearly twelve months of negotiations between the two bodies the Infirmary Board at its last meeting declared themselves unable to accept the conditions proposed, and the trustees have now withdrawn their offer. It is an open secret that the relations between the College and the Infirmary have for some time been considerably strained. The College authorities, as representing the medical school, desire to have some control over or voice in the arrangements for the clinical instruation provided for their students, but this the Infirmary has not been willing to accede to; other matters also have caused no inconsiderable friction between the two bodies, but it is to be hoped that in the interests of the Infirmary, the College, and the public at large, some modus vivend $i$ may ere long be arrived at, and that this handsome proffered gift may not be irretrievably lost.

Salford and its Fever Hospital.

$O$ wing to the great prevalence at the present time of scarlet fever and diphtheria in the neighbouring borough, great difficulty has arisen in providing hospital accom. modation for all the cases which it is desirable to isolate; and it was stated last week that the wards of the Wilton Hospital are crowded far beyond their proper accommodation. If this be so, it is no light matter; for of all patients those suffering from infectious disease are the last that should be stinted in the proper cubic space and air-supply within their wards. In Manchester itself the cases of scarlet fever are also so numerous that the Infirmary Fever Hospital cannot take the surplus Salford patients; and hence the health authorities of the latter are seeking the help of the guardians to provide them with hospital accommodation at Hope. In the meantime the proposed new fever hospital for the Salford Corporation is still in the clouds.

Prevalence of Scarlet Fever.

During the present epidemic of scarlet fever, and now that the notification of infectious disease can, by means of the recent new Act, be easily put in operation, it is to be hoped that all the surrounding smaller districts will at once put it in force, and the whole of the population comprised in "Greater Manchester" thus be placed under the same conditions, so far as obtaining knowledge of the. existence of these diseases is concerned.

\section{Unhealthy Dwellings.}

At last the Corporation has made a distinct move in grappling with this subject. At the last meeting of the City Council a "presentment" was made by the medical officer, condemning what has long been known as one of the most insanitary areas in the Ancoats district. It was this area to which Dr. Thresh a short time ago drew particular attention in a special report that he made thereon to the sanitary association. It is pleasing to note that Dr. Thresh's work has not gone unnoticed, and he has just been appointed officer of health to Chelmsford.

Manchester, Oct. 8 th 